\title{
POLUIÇÃO POR LIXO NAS PRAIAS DE ABRÃ̃o E PRETA NA BORDA SETENTRIONAL-ORIENTAL DA ILHA GRANDE (ANGRA DOS REIS, RJ) E O IMPACTO SOCIO-AMBIENTAL
}

\author{
Andrea Viana Macedo ${ }^{(a)}$, André Luiz Carvalho da Silva ${ }^{(b)}$, Emanuelle Assunção Loureiro \\ Madureira $^{(\mathrm{c})}$, Carolina Perreira Silvestre $^{(\mathrm{d})}$ \\ (a) Departamento de Geografia da Universidade do Estado do Rio de Janeiro - FFP-UERJ, vmacedo.avm@ @mail.com \\ (b)Departamento de Geografia da - UERJ, andrelcsilvageouerj@gmail.com \\ (c)Departamento de Geografia da - UERJ, manumadureira.uerj@gmail.com \\ (d)Dinâmica dos Oceanos e da Terra da Universidade Federal Fluminense - UFF, carolinasilvestregeouff@gmail.com
}

\section{Eixo: DINÂMICA E GESTÃO DE ZONAS COSTEIRAS}

\begin{abstract}
Resumo
O presente trabalho objetivou compreender os usos relacionados a distribuição, composição e fonte de resíduos sólidos nas praias de Abraão e Preta no litoral setentrional-oriental da Ilha Grande em Angra dos Reis (RJ). Essa área impressiona pela beleza natural e biodiversidade que atrai turistas do Brasil e do mundo, o que tem gerado problemas relacionados a produção de lixo na ilha. Os monitoramentos foram realizados nas estações de inverno (2015) e verão (2016), em dois locais na praia de Abraão e um na praia Preta. Plásticos, cigarros e restos de obras foram os materiais mais encontrados nas praias estudadas. Apesar da coleta diária, observou-se a presença de lixo em ambas as praias, com destaque para o setor sudeste de Abraão, onde a estrutura voltada para o turismo é maior. Na praia Preta, embora localizada dentro do PEIG, o lixo encontrado é deixado em grande parte por frequentadores.
\end{abstract}

Palavras chave: Iha Grande, dinâmica costeira, lixo marinho, plástico, uso e ocupação.

\section{Introdução}

O litoral da Ilha Grande, no município de Angra dos Reis, estado do Rio de Janeiro (Figura 1), recebe uma grande quantidade de turistas durante o ano todo, sendo maior nos meses mais quentes, o que tem contribuído para o acúmulo de lixo na ilha. Esse lixo oferece riscos para os banhistas e compromete a qualidade ambiental da região, uma vez que esses materiais podem causar problemas devido à proliferação de animais transmissores de doenças, poluição visual e risco à saúde dos frequentadores (SANTOS et al., 2008). Este cenário demanda ações voltadas para a preservação dos diversos ecossistemas presentes na ilha e a manutenção das atividades de subsistência da população local. Diante do exposto, este estudo objetivou compreender os usos relacionados a distribuição, composição e origem do lixo encontrado nas praias de Abraão e Preta, ambas localizadas no litoral setentrional-oriental da Ilha Grande, em Angra dos 
XVII Simpósio Brasileiro de Geografia Fisica Aplicada

I Congresso Nacional de Geografia Física
OS DESAFIOS DA GEOGRAFIA FÍSICA NA FRONTEIRA DO CONHECIMENTO

Instituto de Geociências - Unicamp

Campinas - SP

28 de Junho à 02 de Julho de 2017

Reis (RJ) (Figura 1C). Logo, foi necessário quantificar, classificar e avaliar o estado de conservação do lixo encontrado na faixa de areia emersa das praias entre as estações de inverno (2015) e verão (2016).
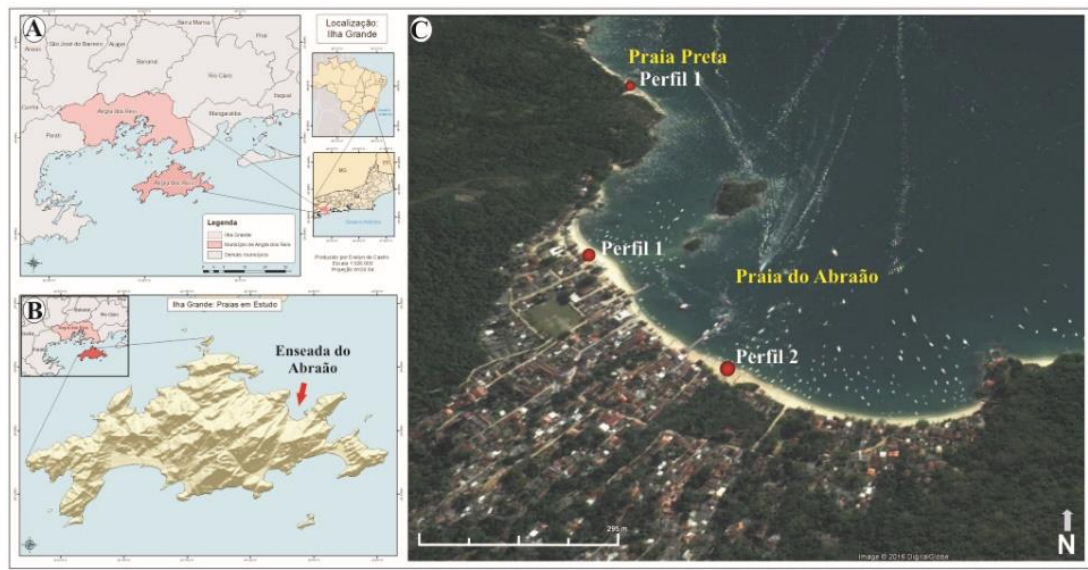

Figura 1 - Localização da área de estudo. Fonte: Google Earth (2017).

As praias da Ilha Grande apresentam características geográficas e geomorfológicas bem distintas. Essas praias apresentam diferentes graus de exposição à aproximação de ondas e aos eventos de tempestades, dependendo da localização e orientação das mesmas (GODOY et al., 2011). A praia do Abraão (Figura 1C), com $1.200 \mathrm{~m}$ de extensão, apresenta uma baixa dinâmica por estar abrigada e voltada para o continente (GRALATO et al. 2015). Esta é uma das praias mais frequentadas, por ser o ponto de embarque e desembarque de passageiros e mercadorias, com intensa movimentação de embarcações de pequeno e médio porte e também por concentrar a maior parte da infraestrutura de hospedagem, comércio e serviços disponível, além das residências. Encaixada entre promontórios, a praia Preta (Figura 1C) possui apenas 300 m de extensão e está localizada dentro Parque Estadual da Ilha Grande (PEIG) na Vila do Abraão. Por se tratar de uma Unidade de Conservação, nessa área não há residências e nem mesmo estruturas voltadas para o turismo. As areias da praia são constituídas em grande parte por minerais pesados na cor preta (magnetita, ilmenita, rutilo, etc.), característica que deu origem ao nome da praia.

\section{Metodologia}

O monitoramento do lixo marinho pode ser realizado de três formas: (1) amostragem na profundidade do oceano, (2) na superfície oceânica e (3) na área costeira (SANTOS et al., 2008). Essa última foi empregada neste estudo por ser a mais barata e, consequentemente, de ampla utilização em estudos dessa natureza (SANTOS et al., 2008; BAPTISTA NETO e FONSECA, 2011). Para tal, foram realizados trabalhos de campo nas estações de inverno (2015) e verão (2016) para a contagem, identificação e classificação dos resíduos sólidos presentes na faixa de areia emersa da praia. Foram selecionados 3 
pontos de monitoramento, sendo 2 na praia de Abraão e um na praia Preta (Figura 1C). Os locais foram definidos com base na extensão e nas diferentes formas de uso relacionadas a cada uma das praias estudadas. Foram selecionadas áreas sobre o pós-praia com dimensões de 25 x 50 metros. O material encontrado em cada uma das praias estudadas foi devidamente contado, catalogado e fotografado, para posterior caracterização do lixo e verificação do estado de conversação destes materiais.

\section{Resultados e discussão}

Os resultados dos monitoramentos realizados nas praias durante as estações de inverno de 2015 e verão de 2016, mostram que o setor sudeste (a área do perfil 2) da praia do Abraão é o que apresenta maior quantidade de lixo (Tabela I e Figura 2). Essa área é repleta de restaurantes, pousadas, entre outros estabelecimentos (Figura 3B). Alguns desses restaurantes estão localizados dentro dos limites da praia e utilizam o pós-praia como área externa dos estabelecimentos, com a colocação de cadeiras, mesas e barracas (Figura 3B). O perfil 1 da praia do Abraão (Tabela I e Figura 2) também apresentou grande quantidade de lixo. Essa área tem sido utilizada como estacionamento de embarcações, que chegam a ocupar toda a extensão da praia (Figura 3A). A praia Preta (perfil 1) foi a que apresentou a menor quantidade de lixo (Tabela I e Figuras 2 e 3), provavelmente, devido a ausência de construções nesse trecho, que se encontra localizado dentro de uma Unidade de Conservação (PEIG). A quantidade de lixo encontrado nas praias de Abraão e Preta no inverno de 2015 (417 itens), representa 15\% a mais em relação ao que foi verificado no verão de 2016 (363) (Tabela I e Figura 2). Apesar da grande quantidade de lixo encontrado em ambas as estações, as diferenças são pequenas, o que pode ser explicado pela limpeza frequente dessas praias durante todo o ano. Mesmo nos meses mais frios (inverno) o turismo na Ilha Grande é expressivo e a limpeza das praias é feita rotineiramente pela prefeitura e pelos restaurantes e pousadas nas áreas próximas aos estabelecimentos.

O plástico foi o material residual mais encontrado ao longo das praias de Abraão e Preta, correspondendo a 24\% (186 itens) de todo o lixo encontrado em ambas as estações (Tabela I e Figuras 2 e 3). Nas praias da Baía de Guanabara o plástico também tem sido apontado como predominante e representa $70 \%$ do total (BAPTISTA NETO e FONSECA, 2011), número bem superior ao encontrado nas praias estudadas na Baía da Ilha Grande. O plástico é facilmente transportado, tanto pelas correntes costeiras, quanto pelo vento, e por isso pode ser deslocado por longas distâncias. A sua decomposição é geralmente lenta e pode levar séculos para acontecer (SANTOS et al., 2008). Neste sentido, a predominância de lixo composto por plástico nas praias estudadas representa uma ameaça aos ecossistemas costeiros da Ilha Grande, podendo causar uma série de danos aos animais e contribuir para a degradação desses ambientes. Lixo representado 


\section{OS DESAFIOS DA GEOGRAFIA FÍSICA NA FRONTEIRA DO CONHECIMENTO \\ Instituto de Geociências - Unicamp \\ Campinas - SP \\ 28 de Junho à 02 de Julho de 2017}

por resto de construções, cigarros, madeira modificada e metais diversos aparecem em quantidade significativa e também estão entre os materiais mais encontrados na areia da praia (Tabela I e Figuras 2 e 3). O descarte inadequado desses materiais, assim como, o acúmulo em locais impróprios (no meio das ruas, trilhas, etc.), está diretamente associado à crescente demanda gerada pela intensificação do turismo, conforme ressaltado anteriormente por Prado (2003). A falta de estrutura adequada na ilha para armazenar e transportar a grande quantidade de lixo produzido por um número cada vez maior de frequentadores e, que demanda cada vez mais serviços, representa uma ameaça para os ecossistemas costeiros e marinhos.

Tabela I - Quantidade e composição do lixo nas praias monitoradas no ano de 2015 e 2016.

\begin{tabular}{|c|c|c|c|c|c|c|c|c|c|}
\hline Tipos de lixo & \multicolumn{4}{|c|}{ Praia de Abraão } & \multicolumn{2}{|c|}{ Praia Preta } & \multicolumn{2}{|c|}{ Total } & \multirow{3}{*}{ Total Geral } \\
\hline Estações & \multicolumn{2}{|c|}{ Inverno } & \multicolumn{2}{|c|}{ Verão } & Inverno & Verão & Inverno & Verão & \\
\hline Perfis: & P1 & $\mathrm{P} 2$ & P1 & $\mathrm{P} 2$ & P1 & P1 & 2015 & 2016 & \\
\hline Plástico & 42 & 16 & 68 & 29 & 13 & 18 & 71 & 115 & 186 \\
\hline Vidro & 1 & 20 & 1 & 2 & 0 & 0 & 21 & 3 & 24 \\
\hline Papel/papelão & 5 & 21 & 3 & 6 & 0 & 1 & 26 & 10 & 36 \\
\hline Madeira modificada & 20 & 21 & 5 & 40 & 5 & 1 & 46 & 46 & 92 \\
\hline Metais diversos & 10 & 55 & 10 & 5 & 3 & 1 & 68 & 16 & 84 \\
\hline Matéria orgânica & 5 & 8 & 0 & 3 & 0 & 0 & 13 & 3 & 16 \\
\hline Fezes de animais & 0 & 0 & 0 & 0 & 0 & 0 & 0 & 0 & 0 \\
\hline Lata & 0 & 0 & 0 & 0 & 0 & 0 & 0 & 0 & 0 \\
\hline Borracha & 2 & 0 & 1 & 1 & 2 & 0 & 4 & 2 & 6 \\
\hline Isopor & 3 & 0 & 11 & 14 & 0 & 0 & 3 & 25 & 28 \\
\hline Tecido & 4 & 0 & 1 & 2 & 1 & 3 & 5 & 6 & 11 \\
\hline Nylon & 0 & 0 & 3 & 0 & 0 & 0 & 0 & 3 & 3 \\
\hline Corda & 2 & 3 & 4 & 1 & 0 & 0 & 5 & 5 & 10 \\
\hline Cigarro & 0 & 103 & 1 & 0 & 5 & 14 & 108 & 15 & 123 \\
\hline Restos de construção & 6 & 32 & 0 & 114 & 0 & 0 & 38 & 114 & 152 \\
\hline Outros & 3 & 3 & 0 & 0 & 2 & 0 & 8 & 0 & 8 \\
\hline Total & 104 & 282 & 108 & 217 & 31 & 38 & 417 & 363 & 780 \\
\hline
\end{tabular}

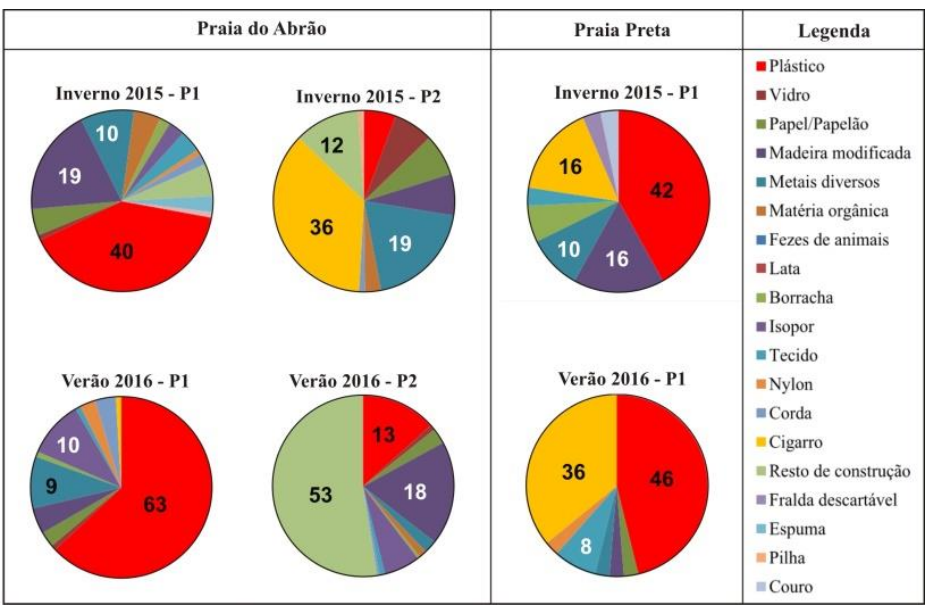

Figura 2- Composição do lixo monitorado nas praias do Abraão e Preta no inverno de 2015 e no verão de 2016. 
XVII Simpósio Brasileiro de Geografia Fisica Aplicada

I Congresso Nacional de Geografia Física
OS DESAFIOS DA GEOGRAFIA FÍSICA NA FRONTEIRA DO CONHECIMENTO

Instituto de Geociências - Unicamp

Campinas - SP

28 de Junho à 02 de Julho de 2017

\section{Conclusões}

As praias de Abraão e Preta na Ilha Grande apresentaram uma quantidade expressiva de lixo na faixa de areia, o que pode causar sérios danos a saúde dos frequentadores e aos diversos ecossistemas costeiros e marinhos. Plásticos, cigarros e restos de obras estão entre os materiais mais encontrados nas praias e estão relacionados aos usos e serviços voltados para o turismo na região. A coleta de lixo e limpeza urbana não são efetuados de forma adequada na Ilha Grande. A estrutura de armazenamento e transporte de lixo na ilha é inadequada, o que causado poluição nas praias e comprometido o equilíbrio dos diversos ecossistemas costeiros e marinhos da região.

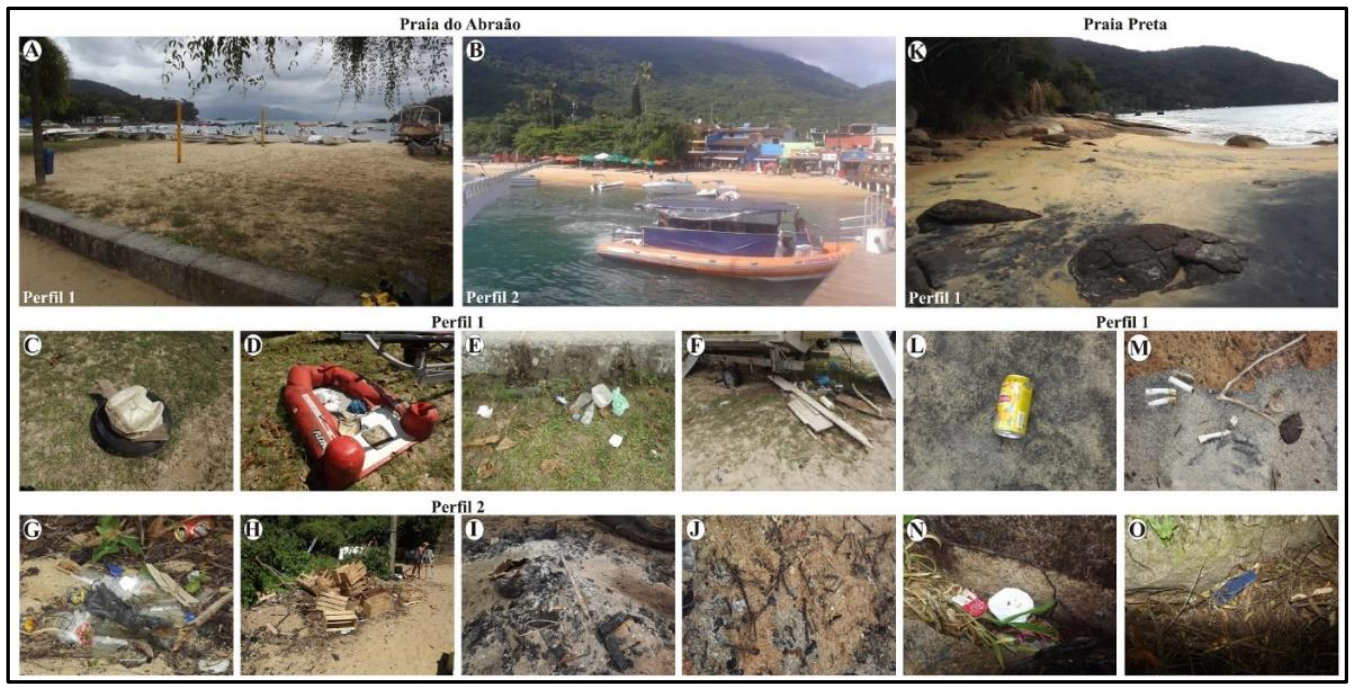

Figura 3- Pontos de monitoramento nas praias de Abraão e Preta no inverno de 2015 e no verão de 2016; e tipos de resíduos encontrados. Fotos: Andrea Macedo $(2015,2016)$.

\section{REFERÊNCIAS}

BAPTISTA NETO, J.A., FONSECA, E.M. 2011. Seasonal, spatial and compositional variation of beach debris along of the eastern margin of Guanabara Bay (Rio de Janeiro) in the period of 1999-2008. J. Journal of Integrated Coastal Zone Management. Vol. 11, pp. 31-39.

GODOI, V. A., CALADO, L., WATANABLE, W. de B., YAGINUMA, L. E., Bastos, M. Evento extremo de ondas na Baía da Ilha Grande: um estudo de caso. Boletim do Observatório Ambiental Alberto Ribeiro Lamego, Campos dos Goytacazes/RJ, v. 5 n. 2, p. 27-44, jul. / dez. 2011.

GRALATO, J. C. A.; SILVA, A. L. C.; SILVESTRE. C. P.; BATISTA, A. S. 2015. Caracterização fisiográfica e textural das praias no litoral oriental da Ilha Grande no município de Angra dos Reis, RJ. Anais do XVI Simpósio de Geografia Física e Aplicada. Teresina, pp. 1720-1727. 


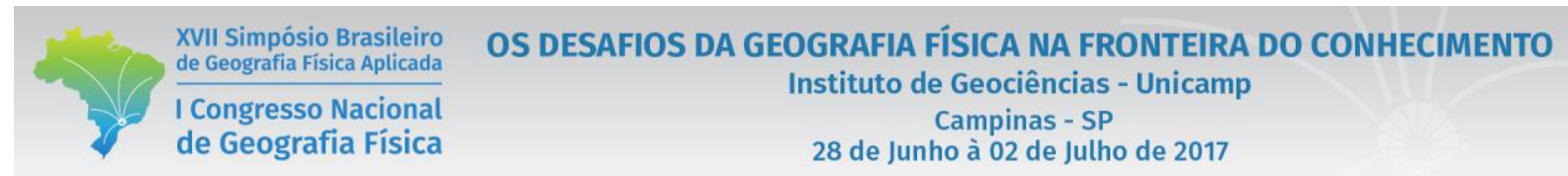

PRADO, R. M. 2003. Tensão no Paraíso: Aspectos da Intensificação do Turismo na Ilha Grande. Caderno Virtual de Turismo. Vol. 3, $\mathrm{N}^{\circ} 1$.

SANTOS, I.R., WALLNER-KERSANACH, M., BAPTISTA NETO, J. A., 2008. Poluição marinha, por resíduos sólidos. pp. 309-330. 